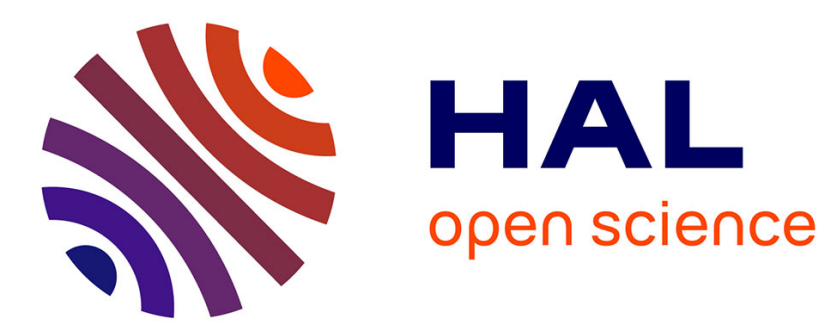

\title{
Influence of evaporation and exchange reactions at the surface on the evolution of an arbitrary tracer distribution by diffusion
}

\author{
R.J. Tarento
}

\section{- To cite this version:}

R.J. Tarento. Influence of evaporation and exchange reactions at the surface on the evolution of an arbitrary tracer distribution by diffusion. Revue de Physique Appliquée, 1989, 24 (1), pp.11-16. 10.1051/rphysap:0198900240101100 . jpa-00246021

HAL Id: jpa-00246021

https://hal.science/jpa-00246021

Submitted on 1 Jan 1989

HAL is a multi-disciplinary open access archive for the deposit and dissemination of scientific research documents, whether they are published or not. The documents may come from teaching and research institutions in France or abroad, or from public or private research centers.
L'archive ouverte pluridisciplinaire HAL, est destinée au dépôt et à la diffusion de documents scientifiques de niveau recherche, publiés ou non, émanant des établissements d'enseignement et de recherche français ou étrangers, des laboratoires publics ou privés. 


\title{
Influence of evaporation and exchange reactions at the surface on the evolution of an arbitrary tracer distribution by diffusion
}

\author{
R. J. Tarento \\ CNRS, Laboratoire de Physique des Matériaux, Meudon, France \\ (Reçu le 24 juin 1988, révisé le 22 septembre 1988, accepté le 11 octobre 1988)
}

\begin{abstract}
Résumé. - La solution de l'équation à une dimension de la diffusion avec évaporation du matériau et échange en surface du traceur avec l'ambiant a été appliquée aux cas de la diffusion en couche épaisse, de la diffusion d'un profil implanté, et de l'échange isotopique.
\end{abstract}

\begin{abstract}
The solution of the equation of one-dimensional diffusion with evaporation of the sample and exchange of the diffusant with the ambient at the surface has been applied to the cases of thick layer diffusion, diffusion from an implantation profile and isotope exchange diffusion.
\end{abstract}

\section{Introduction.}

A diffusion coefficient is obtained by fitting an experimental curve (concentration-vs-depth) to a theoretical one which takes into account different mechanisms occurring during the annealing. Evaporation of the substrate and exchange through the surface between the ambient atmosphere and the sample are processes which quite often occur significantly during diffusion in many materials (semiconductors, oxides) [1], particularly when the penetration depths are small.

Particular diffusion situations have been studied involving evaporation and/or exchange starting from initial profiles which are not general : for instance, Biersack has derived depth distributions of implanted atoms under the influence of evaporation and diffusion [2] ; D. K. Dawson, L. W. Barr and L. W. Pitt-Pladdy have been interested in isotope exchange diffusion considering no evaporation [3]. Recently Routbort and Rothman [4] have given the analytical formula for the thin film diffusion including evaporation and exchange. As it is well known in the case of small penetration (in fact for small diffusion coefficient), the initial profiles obtained with the «thin film method" are often rather thick and implanted profiles are not ideally Gaussian. Hence it is worth tackling the case of most general initial distribution.

The present article deals with the exact solution of the one-dimensional diffusion problem involving evaporation of the sample and isotopic exchange at the surface whatever the initial profile. Part 1 treats the mathematical solution. The general formula has been applied to three cases, which are of great interest since they are the main experimental procedures used to derive diffusion coefficients : thick film diffusion (part 2), diffusion of an implantation profile (part 3) and isotopic exchange diffusion (part 4).

\section{Mathematical problem.}

One-dimensional diffusion with evaporation of the sample is a phenomenon controlled by the Fick second law which is written in the moving frame :

$$
D \frac{\partial^{2} C(x, t)}{\partial x^{2}}+\frac{v \partial C(x, t)}{\partial x}=\frac{\partial C(x, t)}{\partial t}
$$

where

$C(x, t)$ is the concentration of diffusant ;

$t \quad$ the time of diffusion;

$D$ the coefficient of diffusion;

$x \quad$ the distance from the surface;

$v$ the speed of the initial surface due to the evaporation.

We shall assume that exchange of the diffusant with the ambient is controlled by the chemical reaction at the interface such that at each moment, the interface concentration develops to balance the diffusional flux and the convection flux of the 
diffusant ; this condition is mostly verified if the evaporation speed is small. The simplest reasonable assumption is that the rate of exchange is directly proportional to the difference between the actual concentration $C(0, t)$ and the constant surface concentration $\left(C_{1}\right)$ of diffusant in the atmosphere side [1] :

$$
D \frac{\partial C}{\partial x}(0, t)=K\left[C(0, t)-C_{1}\right]
$$

where $K$ is a parameter characterizing the exchange which has been taken independent on time. The second boundary condition is given by the initial profile before diffusion,

$$
C(x, 0)=\phi(x) .
$$

Let $\bar{C}(x, p)$ be the time Laplace transform of $C(x, t)$. From equation (1) we obtain

$$
D \frac{\partial^{2} \bar{C}}{\partial x^{2}}+v \frac{\partial \bar{C}}{\partial x}-p \bar{C}=-\phi(x) .
$$

Two independent solutions of the homogeneous equation are $\mathrm{e}^{-\lambda_{1} x}$ and $\mathrm{e}^{-\lambda_{2} x}$ where :

$$
\lambda_{1,2}=\frac{v}{2 D} \pm \frac{}{\sqrt{D}} \sqrt{p+v^{2} / 4 D} .
$$

A particular solution of the inhomogeneous equation is readily obtained since it is well know that :

$$
U(x, t)=\frac{1}{2} \int_{0}^{\infty} \frac{\mathrm{e}^{-(y-x-v t)^{2} / 4 D t}}{\sqrt{\pi D t}} \phi(y) \mathrm{d} y
$$

is the solution of the Fick equation in an infinite medium with condition (3) alone. The general solution of equation (4) that vanishes at infinity can therefore be written :

$$
\bar{C}(x, p)=A(p) \mathrm{e}^{-\lambda_{1} x}+\bar{U}(x, p)
$$

where $\bar{U}(x, p)$ is the Laplace transform of $U(x, t)$ :

$$
\begin{aligned}
\bar{U}(x, p)=\frac{1}{2} \int_{0}^{x} & \frac{\phi(y)}{\sqrt{D}} \frac{\mathrm{e}^{\lambda_{1}(x-y)}}{\sqrt{p+v^{2} / 4 D}} \mathrm{~d} y+ \\
& +\frac{1}{2} \int_{x}^{\infty} \frac{\phi(y)}{\sqrt{D}} \frac{\mathrm{e}^{\lambda_{2}(x-y)}}{\sqrt{p+v^{2} / 4 D}} \mathrm{~d} y
\end{aligned}
$$

the constant $A(p)$ is obtained using the time Laplace transform of the boundary, condition (2):

$$
D \frac{\bar{C}(0, p)}{\partial x}=K\left(\bar{C}(0, p)-\frac{C_{1}}{p}\right) .
$$

Therefore

$$
\begin{aligned}
A(p)(K+ & \left.\lambda_{1} D\right)= \\
= & \frac{K C_{1}}{p}-\frac{K}{2} \int_{0}^{\infty} \frac{\phi(y)}{\sqrt{D}} \frac{\mathrm{e}^{-\lambda_{2} y}}{\sqrt{p+\frac{v^{2}}{4 D}}} \mathrm{~d} y \\
& +\frac{\lambda_{2} D}{2} \int_{0}^{\infty} \frac{\phi(y)}{\sqrt{D}} \frac{\mathrm{e}^{-\lambda_{2} y}}{\sqrt{p+\frac{v^{2}}{4 D}}} \mathrm{~d} y .
\end{aligned}
$$

Coming back to the time space the general formula for the concentration is :

$$
\begin{gathered}
C(x, t)=\frac{1}{2} \int_{0}^{\infty} \mathrm{e}^{-(y-x-v t)^{2} / 4 D t} \frac{\phi(y) \mathrm{d} y}{\sqrt{\pi D t}}+\frac{1}{2} \int_{0}^{\infty} \exp \left(\frac{v y}{D}\right) \frac{\phi(y)}{\sqrt{\pi D t}} \mathrm{e}^{-(y+x+v t)^{2} / 4 D T} \mathrm{~d} y \\
-\left(H+\frac{v}{2 D}\right) \int_{0}^{\infty} \phi(y) \exp \left(H^{2} D t+H(x+y+v t)\right) \operatorname{erfc}\left(\frac{x+y+v t}{2 \sqrt{D t}}+H \sqrt{D t}\right) \cdot \exp \left(\frac{v y}{D}\right) \mathrm{d} y \\
+C_{1}\left[\frac{H}{2\left(H+\frac{v}{D}\right)} \exp \left(-\frac{v x}{D}\right) \operatorname{erfc}\left(\frac{x-v t}{2 \sqrt{D t}}\right)-\right. \\
\left.-\frac{(H+v / 2 D)}{(H+v / D)} \exp \left(H^{2} D t+H(x+v t)\right) \operatorname{erf}\left(\frac{x+v t}{2 \sqrt{D t}}+H \sqrt{D t}\right)\right]
\end{gathered}
$$

where $H=K / D$.

With the formula (11), we can deal with the problem of diffusion occurring with evaporation of the material and exchange at the surface for any tracer distribution.

In the following, we have studied some particular cases.

\section{Thin- or thick-layer initial condition.}

If $\phi(y)$ is equal to $Q_{0} \delta(y)$ (initial thin film condition), from equation (11), we find again the Routbort and Rothman solution [4] : 
$C(x, t)=Q_{0}\left\{\frac{\mathrm{e}^{-(x+v t)^{2} / 4 D t}}{\sqrt{\pi D t}}-\left(H+\frac{v}{2 D}\right) \exp \left[H^{2} D t+H(x+v t)\right] \cdot \operatorname{erfc}\left(\frac{x+v t}{2 \sqrt{D t}}+H \sqrt{D t}\right)\right\}$.

What happens with a thick film ? Let $C_{0}$ and $a$ be respectively the concentration and the thickness of the film, $C_{1}$ is nul if we neglect the presence of tracer in the ambiant atmosphere ; from equation (11) we have :

$$
\begin{aligned}
C(x, t) & =\frac{C_{0}}{2}\left[\operatorname{erf}\left(\frac{a-x-v t}{2 \sqrt{D t}}\right)+\operatorname{erf}\left(\frac{x+v t}{2 \sqrt{D t}}\right)\right]+\frac{C_{0}}{2} \mathrm{e}^{-v x / D}\left[\operatorname{erf}\left(\frac{a+x-v t}{2 \sqrt{D t}}\right)-\operatorname{erf}\left(\frac{x-v t}{2 \sqrt{D t}}\right)\right] \\
- & C_{0} \frac{(H+v / 2 D)}{(H+v / D)} \mathrm{e}^{H^{2} D t+H(x+v t)}\left[\mathrm{e}^{\left(\frac{v}{D}+H\right) a}-1\right]+C_{0} \frac{(H+v / 2 D)}{(H+v / D)} \mathrm{e}^{-\left(H^{2} D t+2 v t H+\frac{v}{D} x+\frac{v_{y}^{2}}{D}\right)} \\
& \times\left\{\mathrm{e}^{\left(\frac{v}{D}+H\right)(x+v t+2 H D t)}\left[-\operatorname{erf}\left(\frac{x+v t+2 H D t}{2 \sqrt{D t}}\right)+\mathrm{e}^{\left(\frac{v}{D}+H\right) a} \operatorname{erf}\left(\frac{x+a+v t+2 H D t}{2 \sqrt{D t}}\right)\right]\right. \\
- & \left.\mathrm{e}^{D t\left(\frac{v}{D}+H\right)^{2}}\left[\operatorname{erf}\left(\frac{x+a-v t}{2 \sqrt{D t}}\right)-\operatorname{erf}\left(\frac{x-v t}{2 \sqrt{D t}}\right)\right]\right\} .
\end{aligned}
$$

Such a situation can be illustrated by oxygen self diffusion experiments in cobalt oxide. For a temperature of $1473 \mathrm{~K}$ the diffusion coefficient has a magnitude of $5 \times 10^{-14} \mathrm{~cm}^{2} / \mathrm{s}$ [5]. At first, neglect evaporation of the sample $(v=0 \mathrm{~cm} / \mathrm{s})$, and consider a high exchange rate $(\mathrm{H})$. Figure 1 displays the time evolution for a $10^{2}$ nanometer film. It is worth noticing that the longer the annealing time, the smoother the maximum. After 1 hour of diffusion, it is located at $x=2 \times 10^{2} \mathrm{~nm}$ and after $10 \mathrm{~h}$ at $x=6 \times 10^{2} \mathrm{~nm}$. For a low exchange rate case, the time evolution looks as it would be without the evaporation phenomenon (Fig. 2). Note that for large penetration the slope of the curve is nearly independent of $H$.

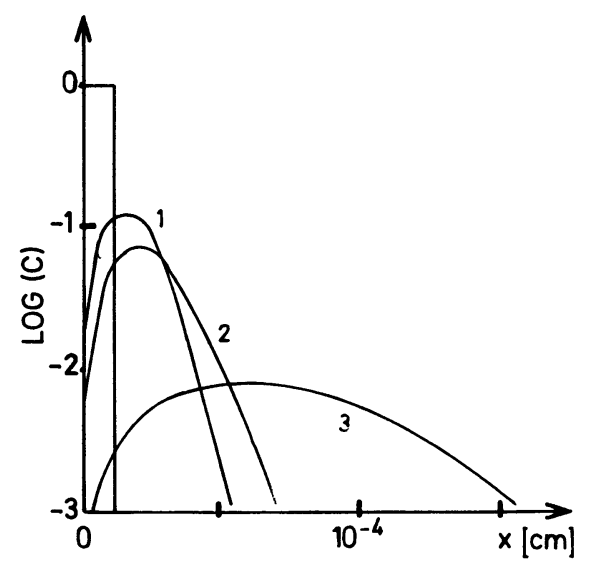

Fig. 1. - Thick layer diffusion : time evolution (exchange but no evaporation phenomenon) $H=10^{6} \mathrm{~cm}^{-1}, D=$ $5 \times 10^{-14} \mathrm{~cm}^{2} / \mathrm{s}, V=0 \mathrm{~cm} / \mathrm{s}$ plot (1) $T=2000 \mathrm{~s}$, plot (2) $T=3600 \mathrm{~s}$, plot (3) $T=3600 \mathrm{~s}$.

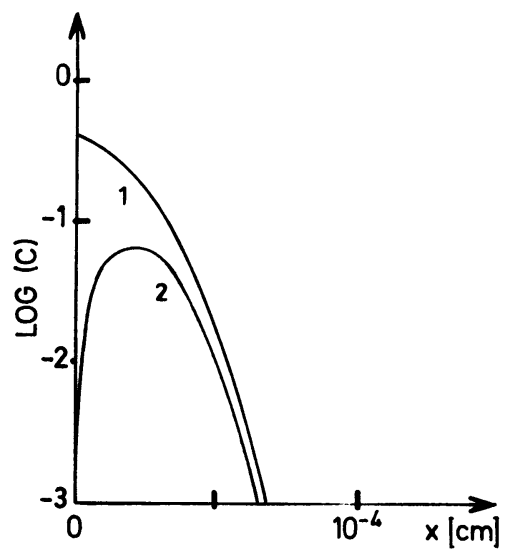

Fig. 2. - Thick layer diffusion (no evaporation) : exchange dependency $D=5 \times 10^{-14} \mathrm{~cm}^{2} / \mathrm{s}, \quad V=0 \mathrm{~cm} / \mathrm{s}$, $T=3600 \mathrm{~s}$, plot (1) $H=10 \mathrm{~cm}^{-1}$, plot (2) $H=10^{6} \mathrm{~cm}^{-1}$.

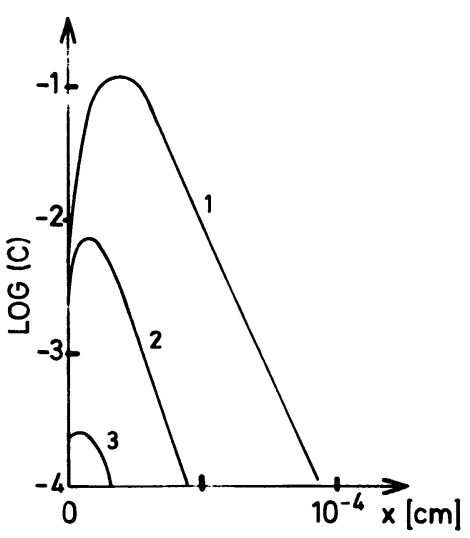

Fig. 3. - Thick layer diffusion with evaporation, time $36000 \mathrm{~s} ; D=5 \times 10^{-14} \mathrm{~cm}^{2} / \mathrm{s}, \quad H=10^{6} \mathrm{~cm}^{-1}$, plot (1) $V=0 \mathrm{~cm} / \mathrm{s}$, plot (2) $V=5 \times 10^{-9} \mathrm{~cm} / \mathrm{s}$, plot (3) $V=$ $10^{-8} \mathrm{~cm} / \mathrm{s}$. 
Let us new consider the evaporation. For a high exchange rate, (Fig. 3) the greater the evaporation speed, the nearer the maximum is to the surface. However for large evaporation speed, the curve looks similar, but the magnitude of the concentration is lower. Therefore the curve obtained by relative concentration measurement should also be studied as a function of time to see if evaporation happens. We have applied the formula to experiments on self diffusion of ${ }^{18} \mathrm{O}$ in cobalt oxide and we have found a good agreement as we show in figure 4. More details are given in reference [5].

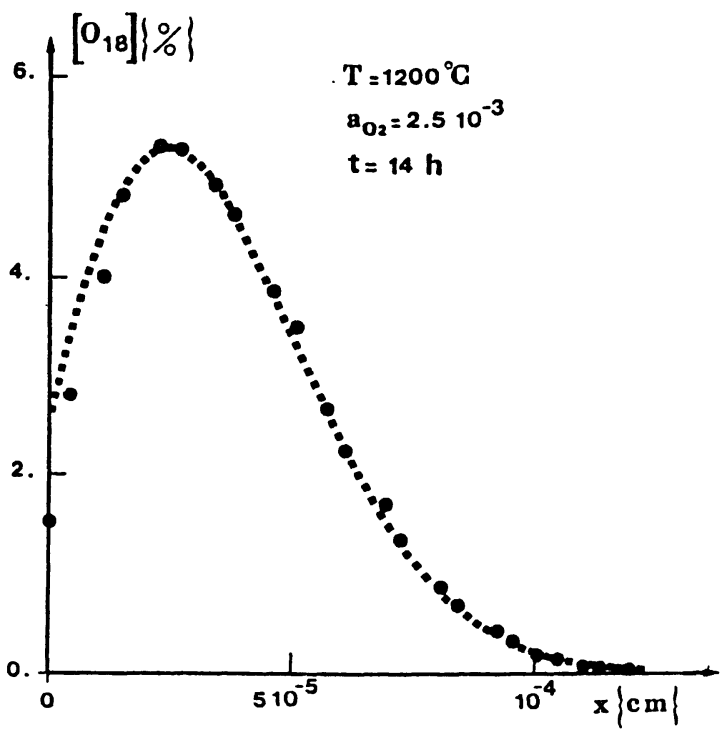

Fig. 4. - Fitting for the $\mathrm{O}^{18}$ self diffusion cn cobalt oxide $\left(T=1200^{\circ} \mathrm{C}, P=0.21 \mathrm{~atm}\right)$.

\section{Diffusion from an implantation profile.}

This method is increasingly used to obtain the diffusion coefficients. The general formula (11) gives the possibility to study the evolution of all types of initial distribution by numerical integrations. Nevertheless to illustrate the behaviour we have taken an example in which the implanted profile can be written analytically as :

$$
\phi(x)=\exp \left(-\left(x-x_{0}\right)^{2} / 2 \sigma_{0}^{2}\right)
$$

where

$$
x_{0}=2 \times 10^{-5} \mathrm{~cm}, \quad \sigma_{0}=0.4 \times 10^{-5} \mathrm{~cm} .
$$

Figures 5 and 6 give time evolution for diffusion with no evaporation, respectively for $D=5 \times 10^{-14}$ and $5 \times 10^{-15} \mathrm{~cm}^{2} / \mathrm{s}$. Due to surface and exchange phenomena, the Gaussian initial profile changes greatly for a long time of diffusion, but not for a short time : we can assume a Gaussian profile. For $D=5 \times 10^{-15} \mathrm{~cm}^{2} / \mathrm{s}$ the maximum of the Gaussian

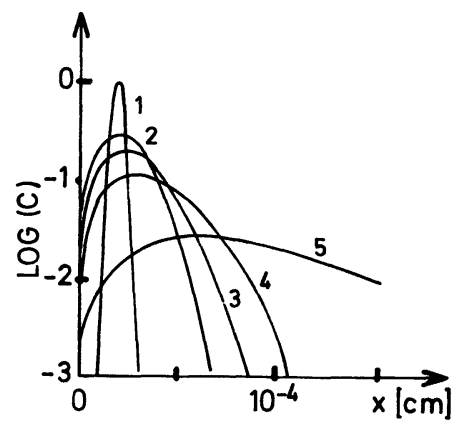

Fig. 5. - Diffusion from an implantation profile : time evolution (no evaporation). $V=0 \mathrm{~cm} / \mathrm{s}, \quad \mathrm{D}=$ $5 \times 10^{-14} \mathrm{~cm}^{2} / \mathrm{s}, H=10^{6} \mathrm{~cm}^{-1}$, plot (1) $T=0 \mathrm{~s}$, plot (2) $T=1800 \mathrm{~s}$, plot (3) $T=3600 \mathrm{~s}$, plot (4) $T=3 \mathrm{~h}$, plot(s) $T=10 \mathrm{~h}$

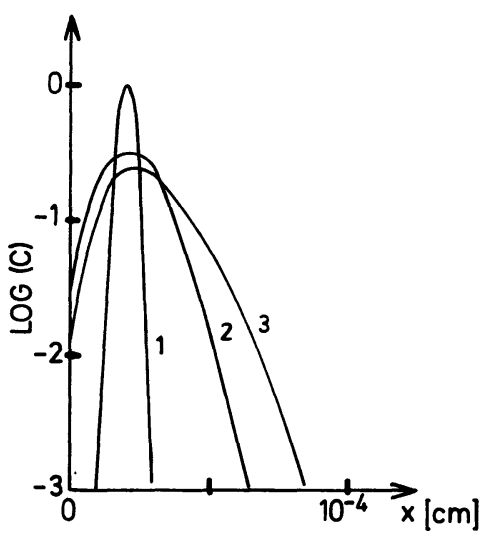

Fig. 6. - Diffusion from an implantation profile : time evolution $\quad V=0 \mathrm{~cm} / \mathrm{s}, \quad D=5 \times 10^{-15} \mathrm{~cm}^{2} / \mathrm{s}, \quad H=$ $10^{6} \mathrm{~cm}^{-1}$, plot (1) $T=0 \mathrm{~s}$, plot (2) $T=4 \mathrm{~h}$, plot (3) $T=10 \mathrm{~h}$.

remains at its initial position for an annealing time of 5 hours; for longer times, it moves away from the surface and as is known, the Gaussian becomes broader. For an infinite sample, the width of the Gaussian is given by

$$
\sigma^{2}(t)=\sigma_{0}^{2}+2 D t .
$$

In our case $\left(D=5 \times 10^{-15} \mathrm{~cm}^{2} / \mathrm{s}\right)$, fitting this formula to the numerical results gives

$$
\sigma^{2}=(0.48)^{2}+2 \times 6.12 \times 10^{-5} t \quad\left(10^{-10} \mathrm{~cm}^{2}\right)
$$

so that the fitted value of $D\left(6.12 \times 10^{-5} \mathrm{~cm}^{2} / \mathrm{s}\right)$ agrees quite well with the known value. This means that equation (14) gives a satisfactory method of analysing experimental results.

Taking into account of the evaporation, the greater the evaporation, the more displaced the peak is towards the surface (Figs. 7, 8). For long diffusion times, the peak magnitude and slope vary greatly, 


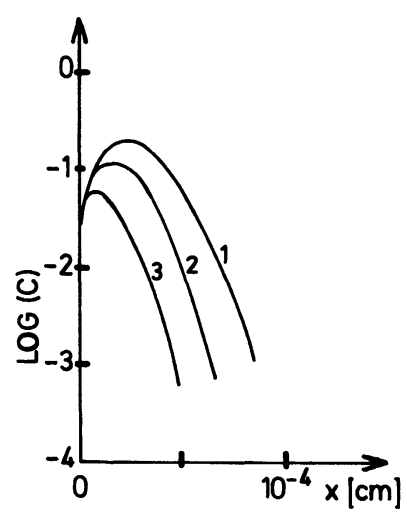

Fig. 7. - Diffusion from an implantation profile : evaporation dependency. $D=5 \times 10^{-14} \mathrm{~cm}^{2} / \mathrm{s}, H=10^{6} \mathrm{~cm}^{-1}$, $T=1 \mathrm{~h}$, plot (1) $V=0 \mathrm{~cm} / \mathrm{s}$, plot (2) $V=5 \times 10^{-9} \mathrm{~cm} / \mathrm{s}$, plot (3) $V=10^{-8} \mathrm{~cm} / \mathrm{s}$.

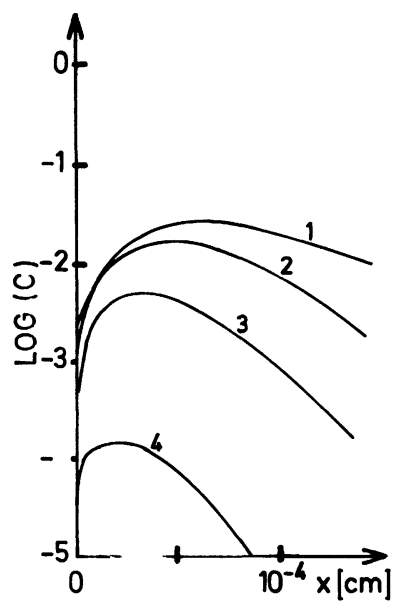

Fig. 8. - Diffusion from an implantation profile ; evaporation dependency. $D=5 \times 10^{-14} \mathrm{~cm}^{2} / \mathrm{s}, H=10^{6} \mathrm{~cm}^{-1}$, $T=10 \mathrm{~h}$, plot (1) $V=0 \mathrm{~cm} / \mathrm{s}$, plot (2) $V=10^{-9} \mathrm{~cm} / \mathrm{s}$, plot (3) $V=2.5 \times 10^{-9} \mathrm{~cm} / \mathrm{s}$, plot (4) $V=5 \times 10^{-9} \mathrm{~cm} / \mathrm{s}$.

whereas for short times, the peak magnitude is nearly constant and the slope can be considered constant.

\section{Isotope exchange diffusion.}

The profile for an exchange between gas and solid is obtained from equation (11)

$$
\begin{aligned}
& \frac{C-C_{0}}{C_{1}-C_{0}}=\frac{1}{2} \operatorname{erfc}\left(\frac{x+v t}{2 \sqrt{D t}}\right)- \\
& \quad-\mathrm{e}^{H^{2} D t+H x+H v t} \operatorname{erfc}\left(\frac{x+v t}{2 \sqrt{D t}}+H \sqrt{D t}\right) \\
& \quad+\frac{1}{2} \frac{H}{\left(H+\frac{v}{D}\right)} \cdot \mathrm{e}^{-\frac{v x}{D}} \operatorname{erfc}\left(\frac{x-v t}{2 \sqrt{D t}}\right) \\
& C_{1}=\text { concentration in the gas ; } \\
& C_{0}=\text { initial concentration in the sample. }
\end{aligned}
$$

REVUE DE PHYSIQUE APPLIQUÉE. - T. 24, N` 1, JANVIER 1989
For $v=0$, we find again the known solution [3]. Figure 9 gives time evolution for isotopic exchange diffusion with no evaporation. Figure 10 displays the dependence of the time evolution on the evaporation speed. The slope is dependent on the evaporation speed. Notice that curves 3 (Fig. 9) and 2 (Fig. 10) look similar. Time evolution studies are necessary in order to eliminate ambiguity.

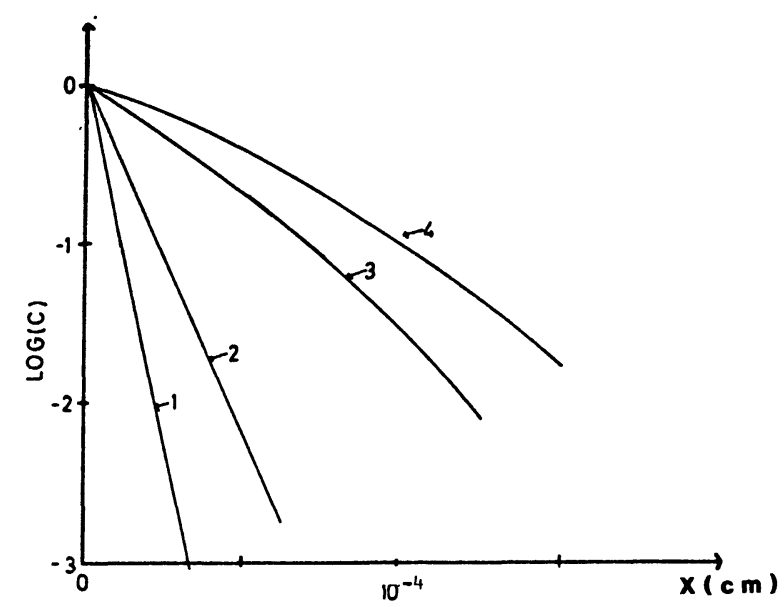

Fig. 9. - Isotopic exchange diffusion time evolution (no evaporation) $D=5 \times 10^{-14} \mathrm{~cm}^{2} / \mathrm{s}, H=10^{6} \mathrm{~cm}^{-1}, V=$ $0 \mathrm{~cm} / \mathrm{s}$, plot (1) $T=0.5 \mathrm{~h}$, plot (2) $T=1 \mathrm{~h}$, plot (3) $T=5 \mathrm{~h}$, plot (4) $T=10 \mathrm{~h}$.

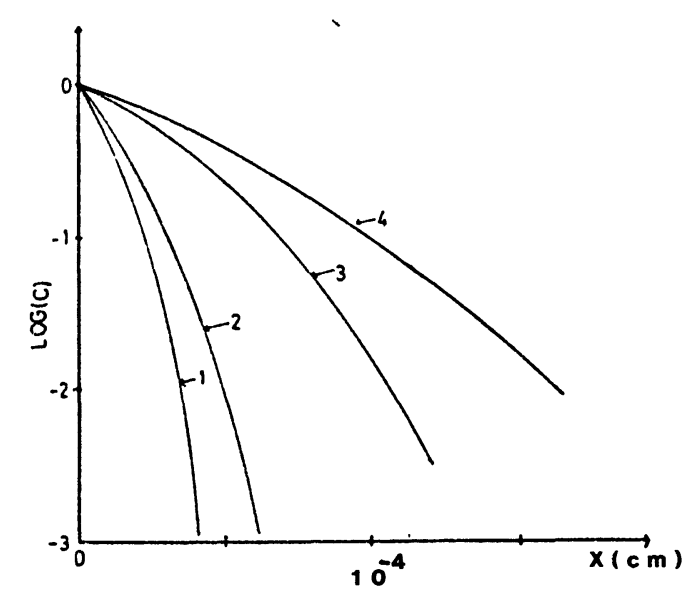

Fig. 10. - Isotopic exchange diffusion : evaporation dependency. $D=5 \times 10^{-14} \mathrm{~cm}^{2} / \mathrm{s}, H=10^{6} \mathrm{~cm}^{-1}, T=10 \mathrm{~h}$, plot (4) $V=0 \mathrm{~cm} / \mathrm{s}$, plot (3) $V=10^{-9} \mathrm{~cm} / \mathrm{s}$, plot (2) $V=5 \times 10^{-9} \mathrm{~cm} / \mathrm{s}$, plot (1) $V=10^{-8} \mathrm{~cm} / \mathrm{s}$.

\section{Conclusion.}

We have derived a general formula, taking account of the influence of evaporation and exchange reactions at the surface on the evolution of tracer distributions by diffusion, which we have applied to the main experimental procedures used to measure 
the diffusion coefficient : thin or thick tracer layer, implantation profiles or gas/solid exchange.

The present article emphasizes the necessity to be careful when exchange and evaporation phenomena occur. It is obvious that we need to fit over the whole diffusion profile. The study of time evolution is a good way to eliminate any ambiguity. Moreover, an initial profile has never an ideal geometric form, but it could be obtained by experimental analysis (SIMS) and its time evolution is given by our formula. It seems that a good case where the experimental study could be performed if the chromium oxydation, where evaporation is important.

\section{Acknowledgements.}

The author is grateful to Dr. M. Gillan, Dr. Harding, F. Nicolas and Dr. C. Monty for their comments and discussion.

\section{References}

[1] CRANK, J., The mathematics of diffusion (Clarendon) 1975.

[2] BiersaCK, J. P., Radiat. eff. 19 (1973) 249.

[3] Dawson, D. K., BARR, L. W. and Pitt-Pladdy, Brit., J. Appl. Phys. 17 (1966) 657.
[4] Routbort, J. L. and Rothman, S. J., Diff. Defect data 40 (1985) 1.

[5] Tarento, R. J. and MonTY, C., Solid State Ionics (1988) in press. 